\title{
In Situ Atom Probe Tomography Study of The Influence of Deformation on Early Stages of Oxidation of Fe18Cr10Ni Alloy
}

Arun Devaraj ${ }^{1}$, Sten Lambeets ${ }^{2}$, Matthew Olszta ${ }^{2}$, Tingkun Liu ${ }^{3}$, Joshua Silverstein ${ }^{3}$ and Daniel Perea ${ }^{4}$

${ }^{1}$ PNNL, United States, ${ }^{2}$ Pacific Northwest National Laboratory, Washington, United States, ${ }^{3}$ Pacific Northwest National Lab, Richland, Washington, United States, ${ }^{4}$ EMSL at PNNL, United States

Improved analysis of stress corrosion crack tip microstructure of steels has been facilitated in the last decade by the advent of site-specific sample extraction methods using dual beam focused ion beam scanning electron microscope (FIB-SEM), as well as by developments in analytical transmission electron microscopy (TEM) and atom probe tomography (APT) cracks.[1-5] Given the multiscale nature of stress corrosion cracking (SCC) mechanisms of steels, implementation of such advanced microstructural characterization methods allows examination of the crack tip microstructure at an atomic resolution, facilitating a renaissance in how the atomic-scale mechanisms of SCC are considered. However, such ex situ microstructural characterization studies after SCC testing do not reveal the highly dynamic process occurring at the crack tips. Stress relief and diffusion during unloading and slow cooling after SCC testing and before detailed microstructural characterizations may drive the microstructure away from true in situ conditions. Hence in situ methods can be invaluable for analyzing SCC mechanisms of steels at high resolution.

Aligned towards this goal of developing in situ methods to study fundamental mechanisms of oxidation and corrosion during SCC of steels, in this work, in situ APT experiments are conducted using a unique environmental reactor chamber attached to PNNL's APT [6-8]. The oxidation mechanism of austenite phase from rolled and recrystallized model Fe-18Cr-10Ni alloys are studied using this in situ APT approach (Figure 1(a) and (b) respectively). The difference in internal defect density between the austenite phase in rolled and recrystallized conditions were analyzed using transmission electron microscopy. APT needles fabricated from both conditions were then initially analyzed in APT to obtain an understanding of the influence of deformation induced defects on solute distribution before oxidation. After the initial APT runs, the needles were transferred to the oxidation chamber and oxidized at $300^{\circ} \mathrm{C}$ for $5 \mathrm{~min}$ at $10 \mathrm{mbar}$ oxygen pressure. After the oxidation the samples were immediately transferred back into the analysis chamber and the post oxidation APT analysis revealed the different oxide layers and Ni segregation to the oxide-metal interface (Figure 2). The differences in the oxide distribution between the rolled and recrystallized Fe18Cr10Ni alloy austenite phases revealed how the deformation influences the oxidation kinetics of these alloys. Such in situ oxidation studies using APT can now be correlated to bulk scale SCC crack tip microstructure of these steels to reveal influence of deformation on oxidation and SCC mechanisms [9]. 

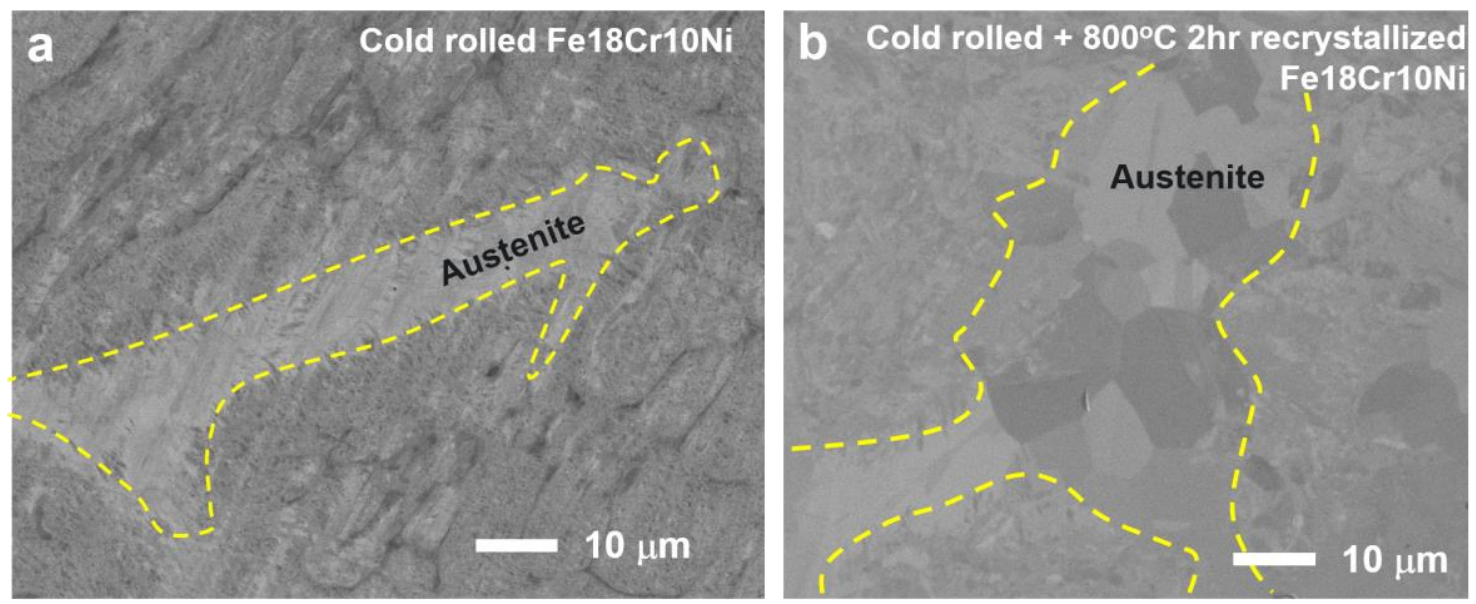

Figure 1. The microstructure of austenite in Fe-18Cr-10Ni alloy in (a) cold-rolled condition and b) after cold rolling and recrystallization annealing at $800^{\circ} \mathrm{C}$ for 2 hours. The yellow dashed lines overlaid in the SEM images highlight the Austenite regions from which the needle samples for in situ APT oxidation were prepared.

\section{Initial run before oxidation}

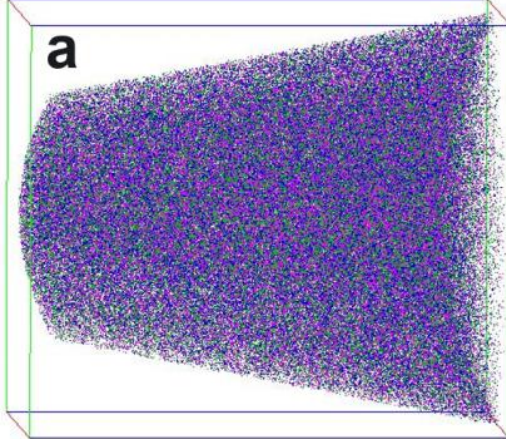

$\mathrm{Fe} \mathrm{Cr} \mathrm{Ni}$ $300^{\circ} \mathrm{C}$

$5 \mathrm{~min}$ $10 \mathrm{mbar}_{2}$

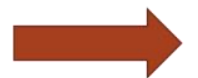

\section{$20 \mathrm{~nm}$}

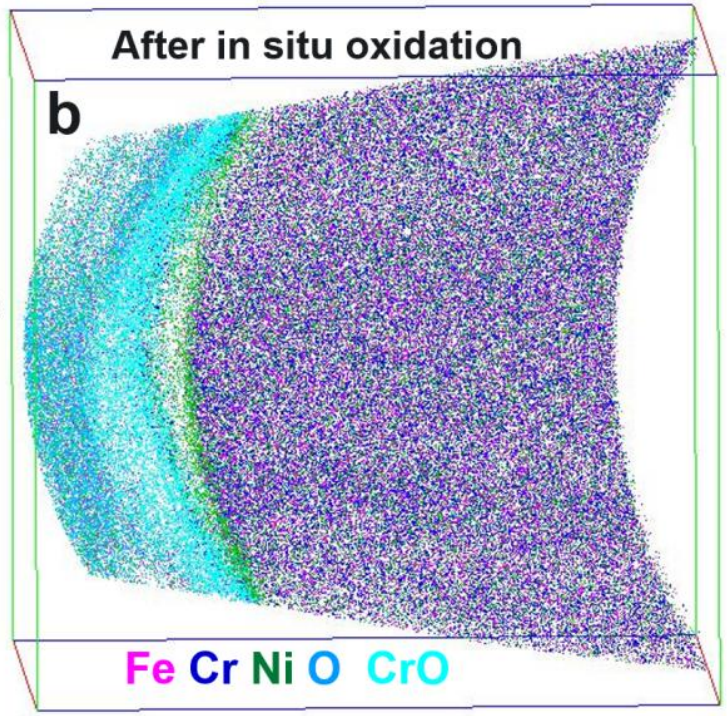

Figure 2. In situ APT results of recrystallized austenite of $\mathrm{Fe}-18 \mathrm{Cr}-10 \mathrm{Ni}$ : a) initial run before oxidation b) after in situ oxidation at $300^{\circ} \mathrm{C}$ for $5 \mathrm{~min}$ at $10 \mathrm{mbar} \mathrm{O}_{2}$

References

[1] S. Lozano-Perez, K. Kruska, I. Iyengar, T. Terachi, T. Yamada, The role of cold work and applied stress on surface oxidation of 304 stainless steel, Corros. Sci. 56 (2012) 78-85.

[2] K. Kruska, S. Lozano-Perez, D.W. Saxey, T. Terachi, T. Yamada, G.D.W. Smith, Nanoscale characterisation of grain boundary oxidation in cold-worked stainless steels, Corros. Sci. 63 (2012) 225233. 
[3] S. Lozano-Perez, K. Kruska, I. Iyengar, T. Terachi, T. Yamada, Understanding surface oxidation in stainless steels through 3D FIB sequential sectioning, Journal of Physics: Conference Series 371 (2012) 012086.

[4] K. Kruska, Understanding the mechanisms of stress corrosion cracking, Oxford University, UK, 2012. [5] M. Meisnar, M. Moody, S. Lozano-Perez, Atom probe tomography of stress corrosion crack tips in SUS316 stainless steels, Corros. Sci. 98 (2015) 661-671.

[6] D.E. Perea, S.S.A. Gerstl, J. Chin, B. Hirschi, J.E. Evans, An environmental transfer hub for multimodal atom probe tomography, Adv. Struct. Chem. Imaging 3(1) (2017) 12.

[7] D.E. Perea, D.K. Schreiber, A. Devaraj, D.D. Reilly, S.V. Lambeets, E.J. Kautz, T.G. Lach, M.G. Wirth, J.E. Evans, Exploring New Science Domains with Atom Probe Tomography Enabled by an Environmental Transfer Hub, Microsc. Microanal. 25(S2) (2019) 276-277.

[8] S.V. Lambeets, E.J. Kautz, M.G. Wirth, G.J. Orren, A. Devaraj, D.E. Perea, Nanoscale Perspectives of Metal Degradation via In Situ Atom Probe Tomography, Topics in Catalysis 63(15) (2020) 1606-1622. [9] This research was supported by the U.S. Department of Energy, Office of Science, Basic Energy Sciences, Materials Sciences and Engineering Division as a part of the Early Career Research program. The in situ APT was conducted using facilities at Environmental Molecular Sciences Laboratory, which is a DOE national user facility funded by Biological and Environmental Research Program located at Pacific Northwest National Laboratory. 